\title{
Ventricular arrhythmias in patients with functional mitral regurgitation and implantable cardiac devices: implications of mitral valve repair with Mitraclip ${ }^{\circledR}$
}

\author{
Tomás Benito-González ${ }^{1}$, Xavier Freixa ${ }^{2}$, Cosmo Godino $^{3}$, Maurizio Taramasso $^{4}$, \\ Rodrigo Estévez-Loureiro, ${ }^{1,5,6}$, Daniel Hernandez-Vaquero ${ }^{7}$, Ana Serrador ${ }^{8}$, Luis Nombela-Franco ${ }^{9}$, \\ David Grande-Prada ${ }^{10}$, Ignacio Cruz-González ${ }^{11}$, Rodolfo San Antonio ${ }^{2}$, Michele Galasso ${ }^{3}$, \\ Mara Gavazzoni ${ }^{4}$, Carmen Garrote ${ }^{1}$, Antonio Portolés-Hernández ${ }^{6}$, Pablo Avanzas ${ }^{7}$, \\ Felipe Fernández-Vázquez ${ }^{1}$, Isaac Pascual ${ }^{7}$
}

${ }^{1}$ Department of Cardiology, University Hospital of León, León, Spain; ${ }^{2}$ Department of Cardiology, Cardiovascular Clinic Institute, Hospital Clinic, University of Barcelona, Barcelona, Spain; ${ }^{3}$ Department of Cardiology, San Raffaele Hospital, Milan, Italy; ${ }^{4}$ Heart Valve Clinic, University Hospital of Zurich, University of Zurich, Zurich, Switzerland; ${ }^{5}$ Department of Cardiology, University Hospital Álvaro Cunqueiro, Vigo, Spain; ${ }^{6}$ Department of Cardiology, University Hospital Puerta de Hierro, Majadahonda, Madrid, Spain; ${ }^{7}$ Heart Área, Hospital Universitario Central de Asturias, Faculty of Medicine, University of Oviedo, Instituto de Investigación Sanitaria del Principado de Asturias (ISPA), Oviedo, Spain; ${ }^{8}$ Department of Cardiology. Biomedical Research Networking Center on Cardiovascular Diseases (CIBERCV), University Clinic Hospital of Valladolid, Valladolid, Spain; ${ }^{9}$ Cardiovascular Institute, Hospital Clínico San Carlos (IdISSC), Madrid, Spain; ${ }^{10}$ Department of Cardiology, University Hospital Virgen de la Victoria, Málaga, Spain; ${ }^{11}$ Department of Cardiology, University Hospital Clínico de Salamanca, Biomedical Research Networking Center on Cardiovascular Diseases (CIBERCV), Biomedical Research Institute of Salamanca (IBSAL), Salamanca, Spain

Contributions: (I) Conception and design: T Benito-González, R Estévez-Loureiro; (II) Administrative support: D Hernandez-Vaquero, P Avanzas, I Pascual; (III) Provision of study materials or patients: All authors; (IV) Collection and assembly of data: All authors; (V) Data analysis and interpretation: T Benito-González, R Estévez-Loureiro; (VI) Manuscript writing: All authors; (VII) Final approval of manuscript: All authors.

Correspondence to: Rodrigo Estévez-Loureiro, MD, PhD, FESC. Interventional Cardiology Unit, Álvaro Cunqueiro Hospital, C/Clara Campoamor 341, 36312 Vigo, Vigo, Spain. Email: roiestevez@hotmail.com.

Background: Limited information has been reported regarding the impact of percutaneous mitral valve repair (PMVR) on ventricular arrhythmic (VA) burden. The aim of this study was to address the incidence of VA and appropriate antitachycardia implantable cardiac defibrillator (ICD) therapies before and after PMVR.

Methods: We retrospectively analyzed all consecutive patients with heart failure with reduce left ventricular ejection fraction (LVEF), functional mitral regurgitation (FMR) grade 3+ or 4+ and an active ICD or cardiac resynchronizer who underwent PMVR in any of the eleven recruiting centers. Only patients with complete available device VA monitoring from one-year before to one year after PMVR were included. Baseline clinical and echocardiographic characteristics were collected before PMVR and at 12-months follow-up.

Results: Ninety-three patients $(68.2 \pm 10.9$ years old, male $88.2 \%)$ were enrolled. PMVR was successfully performed in all patients and device success at discharge was $91.4 \%$. At 12-month follow-up, we observed a significant reduction in mitral regurgitation severity, NT-proBNP and prevalence of severe pulmonary hypertension and severe kidney disease. Patients also referred a significant improvement in NYHA functional class and showed a non-significant trend to reserve left ventricular remodeling. After PMVR a significant decrease in the incidence of non-sustained ventricular tachycardia (VT) $(5.0 \pm 17.8$ vs. $2.7 \pm 13.5, \mathrm{P}=0.002)$, sustained VT or ventricular fibrillation $(0.9 \pm 2.5$ vs. $0.5 \pm 2.9, \mathrm{P}=0.012)$ and ICD antitachycardia therapies $(2.5 \pm 12.0$ vs. $0.9 \pm 5.0, \mathrm{P}=0.033)$ were observed.

Conclusions: PMVR was related to a reduction in arrhythmic burden and ICD therapies in our cohort.

Keywords: MitraClip ${ }^{\circledR}$; ventricular arrhythmias; implantable cardiac devices; heart failure with reduced ejection fraction; functional mitral regurgitation (FMR) 
Submitted Jan 13, 2020. Accepted for publication Feb 07, 2020.

doi: $10.21037 /$ atm.2020.02.45

View this article at: http://dx.doi.org/10.21037/atm.2020.02.45

\section{Introduction}

Heart failure with reduced left ventricular ejection fraction (HFrEF) represents an increasingly prevalent condition associated with a high risk of adverse outcomes despite advances in HF therapies (1). Ventricular arrhythmias (VA) is a major cause of morbidity and mortality in this population, particularly in patients with advanced HFrEF (2). Functional mitral regurgitation (FMR) is a common finding among these patients, with a prevalence around $50 \%$ in either ischemic or non-ischemic dilated cardiomyopathy (DCM), and prognosis is poor if medically managed $(3,4)$. From a theorical point of view, chronic MR induces volume overload of the left ventricle (LV) leading to LV adverse remodeling and fibrosis, enhanced myocardial stress and progression of HF (5). All these factors have been identified as potential triggers for $\mathrm{VA}$ in patients with $\mathrm{HF}$ and may explain that MR is associated to an increased incidence of VA in patients with $\operatorname{DCM}(6,7)$.

Percutaneous mitral valve repair (PMVR) with MitraClip ${ }^{\circledR}$ (Abbott Vascular, Santa Clara, USA) has proved to effectively reduce FMR in patients with HFrEF (8). Limited information has been reported regarding the impact of PMVR on VA burden $(9,10)$. The aim of this study was to address the incidence of VA and appropriate antitachycardia pacing (ATP) and defibrillation shocks before and after PMVR in patients with HFrEF, FMR and implantable cardiac devices (ID).

\section{Methods}

We retrospectively included all consecutive patients with HF and FMR grade 3+ or 4+ who underwent MitraClip ${ }^{\circledR}$ implantation in any of the eleven participating European centers and fulfilled all the following inclusion criteria: (I) HF symptoms with New York Heart Association (NYHA) functional class $\geq$ II despite guideline-directed optimal medical therapy (GDOMT); (II) left ventricular ejection fraction (LVEF) $\leq 40 \%$; (III) active implantable cardiac defibrillator (ICD) or cardiac resynchronization therapy (CRT) with or without ICD, implanted at least one year before PMVR; (IV) complete available device arrhythmic event monitoring from one-year before to one year after MitraClip ${ }^{\circledR}$. Patients were excluded if they met any of the following exclusion criteria: (I) VT ablation or upgrade procedure for CRT therapy within the 2-year device observation period; (II) loss of follow-up, re-do MitraClip ${ }^{\circledR}$ or cardiac surgery during the first year follow-up after PMVR.

The study was carried out in eleven European highvolume centers. Indication for MitraClip ${ }^{\circledR}$ was discussed in an interdisciplinary heart team including interventional and clinical cardiologists, cardiac surgeons and specialists in cardiovascular imaging. All patients were deemed to be at GDOMT for HF at maximum tolerated doses at the time PMVR was performed according to the referring physician. Preprocedural 2D transthoracic and 3D transesophageal echocardiography were performed in all patients to address morphologic suitability for clip implantation, quantitative MR analysis and LVEF estimation by Simpson biplane method according to the European Association of Cardiovascular Imaging recommendations for heart valve disease and cardiac chambers assessments $(11,12)$. The procedure was performed following standard practices under general anesthesia with fluoroscopic and transesophageal echocardiographic guidance.

Study design is summarized in Figure S1. Baseline characteristics and procedural outcomes were collected. Available NT-proBNP levels, glomerular filtration rate and echocardiographic data, as well as NYHA functional class and concomitant HF medical therapies were gathered before PMVR and at one-year follow-up. For statistical purposes, we followed the methodology reported in the COAPT trials (8) and considered as significant, changes in HF drugs consistent with a new drug class start or discontinuation, an increase by $>100 \%$ or a decrease by $<50 \%$ of preprocedural dose. VA recorded by ID were reviewed within 1-year before and 1-year after PMVR (8). Postprocedural results and clinical adverse events after MitraClip ${ }^{\circledR}$ were defined according to Mitral Valve Academic Research Consortium (MVARC) definitions (13).

Frequency and characteristics of VA in all subjects and ICD antiarrhythmic therapies in case of patients with ICD or ICD-CRT were determined by assessment of clinical follow-up reports, device intracardiac recordings and remote monitoring electronic and local databases. Classification of VA events was performed by local experts 
Table 1 Baseline characteristics of included cohort

\begin{tabular}{lc}
\hline Characteristics & Value \\
\hline Age (years) & $68.2 \pm 10.9$ \\
Men (\%) & 88.2 \\
Diabetes mellitus (\%) & 28.0 \\
Ischemic heart disease (\%) & 60.2 \\
Prior myocardial infarction (\%) & 52.7 \\
Atrial fibrillation (\%) & 52.7 \\
Peripheral artery disease or Stroke (\%) & 19.4 \\
Chronic obstructive pulmonary disease (\%) & 22.6 \\
Chronic kidney disease with GFR $\leq 45$ mL/min (\%) & 43.0 \\
Prior heart failure admission (\%) & 74.2 \\
Implantable cardiac device (\%) & \\
ICD & $1,932 \pm 1,407$ \\
CRT \pm ICD & $29.4 \pm 6.2$ \\
Device stimulation (\%) & $13.1 \pm 13.4$ \\
One chamber & $6.2 \pm 5.1$ \\
Two chambers & 43.0 \\
Three chambers & \\
Time from device implantation (days) & 46.2 \\
Left ventricular ejection fraction (\%) & \\
EuroScore logistic (\%) & \\
\hline EuroScore II (\%) & \\
\hline
\end{tabular}

GFR, glomerular filtration rate; ICD, implantable cardiac defibrillator; $\mathrm{CRT}$, cardiac resynchronization therapy.

according to the following prespecified criteria (14): (I) ventricular tachycardia (VT) was defined as a ventricular tachyarrhythmia with a cycle length between 300-400 ms and was classified as sustained (SVT) or non-sustained (NSVT) depending on duration $\geq$ or $<30$ seconds (but $\geq 4$ beats), respectively; (II) VT with a cycle length between 400-600 ms were also included if considered clinically relevant (documented symptoms or prompting hospital admission or ICD antiarrhythmic therapy); (III) ventricular fibrillation and rapid VT (RVT) were defined as a sustained VT with a cycle length $<300 \mathrm{~ms}$, and analyzed together with SVT; (IV) ATP attempts and shocks in the subgroup of patients with ICD or ICD-CRT were collected only if appropriate (not triggered by any supraventricular arrhythmia or device malfunction).
Continuous variables were summarized as mean \pm standard deviation (SD) or as medians and interquartile range (IQR), and were compared using paired or unpaired Student $t$ tests, or the non-parametric Wilcoxon rank sum tests if the normal distribution the variables could not be demonstrated. Derangement from the normal distribution was assessed with the Shapiro-Wilk test. Categorical variables were described as percentages and compared using Chi-square or Fisher exact tests accordingly to expected frequency over or below 5, respectively. McNemar's or exact binominal tests were used to compare before and after PMVR paired categorical variables depending sample size over or below 25. Survival curves for time-to-event were constructed on the basis of all available follow-up data using Kaplan-Meier estimates and comparisons between groups were performed using the log-rank test. A twotailed $\mathrm{P}$ value $<0.05$ was regarded as statistically significant. Statistical analyses were performed using STATA software version 14.2.

\section{Results}

\section{Study population}

Ninety-three subjects $(68.2 \pm 10.9$ years old, male $88.2 \%)$ with HFrEF, an active ID and FMR grade 3+ or 4+ who underwent PMVR before December 2018 in one of the recruiting centers were enrolled in this study. Baseline characteristics of the population are summarized in Table 1 . Included patients had a severely depressed LV function (LVEF 29.4 \pm 6.2 ) and were severely symptomatic at the time of the procedure so that $89.3 \%$ had been priorly admitted for $\mathrm{HF}$ and/or were in advanced functional class NYHA III-IV.

\section{Procedural outcomes}

PMVR was successfully performed in all patients (technical success $100 \%$ ) and more than one clip was implanted in 51 (53.8\%) cases. All but 1 (98.9\%) patient had a reduction in at least one degree in the severity of preprocedural MR and 90 (96.8\%) subjects presented residual $M R \leq 2+$. Postprocedural mean MV gradient was $2.8 \pm 1.4 \mathrm{mmHg}$ and $3(3.2 \%)$ patients had a mean gradient $>5 \mathrm{mmHg}$. Major complications occurred in 4 (4.3\%) cases: 2 patients had an in-hospital stroke, 1 patient had a cardiac tamponade and 1 patient presented a partial MitraClip ${ }^{\circledR}$ detachment. Overall, device success was $91.4 \%$. 
Table 2 Ventricular arrhythmic burden before and after percutaneous mitral valve repair (events per patient per year) $(n=93)$

\begin{tabular}{lccc}
\hline $\begin{array}{l}\text { Ventricular arrhythmic } \\
\text { events }\end{array}$ & Before PMVR & After PMVR & P value* \\
\hline $\begin{array}{l}\text { Non-sustained } \\
\text { ventricular tachycardia }\end{array}$ & $5.0 \pm 17.8$ & $2.7 \pm 13.5$ & 0.002 \\
$\begin{array}{l}\text { Sustained ventricular } \\
\text { tachycardia or }\end{array}$ & $0.9 \pm 2.5$ & $0.5 \pm 2.9$ & 0.012 \\
$\begin{array}{l}\text { Ventricular fibrillation } \\
\text { Any ventricular }\end{array}$ & $5.9 \pm 17.9$ & $3.2 \pm 15.4$ & $<0.001$ \\
tachycardia & $1.6 \pm 9.0$ & $0.4 \pm 2.2$ & 0.021 \\
$\begin{array}{l}\text { Anti-tachycardia } \\
\text { pacing }\end{array}$ & & & \\
ICD shock & & & \\
Any ICD therapy & $0.8 \pm 3.5$ & $0.5 \pm 2.9$ & 0.235 \\
\hline
\end{tabular}

${ }^{\star}$, Wilcoxon matched-pairs signed-ranks test; ${ }^{\star *}$, among patients with ICD or ICD-CRT.

\section{Arrbythmic outcomes}

Overall, 55 (59.1\%) patients presented at least one VA within the 2-year observation period before and after PMVR. In the year before PMVR, the following VA events were documented: 471 NSVTs in 31 (33.3\%) patients, 85 SVT or VF in 28 (30.1\%) patients, 151 ATPs in $18(19.4 \%)$ patients and 77 appropriate ICD shocks in 19 (20.4\%) patients. In the year after PMVR, we observed the following VA events: 251 NSVTs in 19 (20.4\%) patients, 49 SVT or VF in 15 (16.1\%) patients, 33 ATPs in 10 (10.8\%) patients and 49 appropriate ICD shocks in 12 (12.9\%) patients.

After PMVR a significant reduction in the prevalence and incidence of NSVT (32.3\% vs. 20.4\%, $\mathrm{P}=0.043$; $5.0 \pm 17.8$ vs. $2.7 \pm 13.5$ per patient/year, $\mathrm{P}=0.002)$, SVT or VF $(30.1 \%$ vs. $16.1 \%, \mathrm{P}=0.012 ; 0.9 \pm 2.5$ vs. $0.5 \pm 2.9$ per patient/year, $\mathrm{P}=0.012$ ) and any ICD antitachycardia therapy (31.2\% vs. $18.3 \%, \mathrm{P}=0.023 ; 2.5 \pm 12.0$ vs. $0.9 \pm 5.0$ per patient/ year, $\mathrm{P}=0.033$ ) were observed (Table 2, Figures 1,2). A nonsignificant decrease in the burden of appropriate ATP ( $19.4 \%$ vs. $10.8 \%, \mathrm{P}=0.115 ; 1.6 \pm 9.0$ vs. $0.4 \pm 2.2$ per patient/ year, $\mathrm{P}=0.021)$ or defibrillation shocks $(20.4 \%$ vs. $12.9 \%$, $\mathrm{P}=0.167 ; 0.8 \pm 3.5$ vs. $0.5 \pm 2.9$ per patient/year, $\mathrm{P}=0.235)$ were also noted.

\section{Echocardiographic outcomes}

At one-year follow-up, PMVR was associated with a significant reduction in the degree of MR (Figure $3 A$ ) so that $79.1 \%$ of patients remained with a residual $M R \leq 2+$. Mean transmitral gradient at this point was $3.1 \pm 1.9 \mathrm{mmHg}$. PMVR was also related with a significant reduction in the prevalence of severe pulmonary hypertension $(\mathrm{PH})$ $(\mathrm{P}=0.027)$ and to a non-significant reverse $\mathrm{LV}$ remodeling (Table 3).

\section{Clinical outcomes}

At one-year follow-up, a significant improvement in NYHA functional class $(\mathrm{P}<0.001$, Figure $3 B)$ and a significant reduction in NT-proBNP $(\mathrm{P}=0.010)$ and in the prevalence of advance chronic kidney disease $(\mathrm{CKD})(\mathrm{P}=0.004)$ were found.

\section{Heart failure and antiarrbythmic medical therapy}

Patients were deemed to be at optimal GDOMT at the time PMVR was performed: $89.3 \%$ were on beta-blockers, $86.2 \%$ were either on ACE inhibitors, angiotensin receptor blockers (ARB) or angiotensin receptor-neprilysin inhibitor (ARNI) and 74.2\% were on mineralocorticoid receptor antagonist. Documented changes in HF drugs are displayed in Table 4. No significant differences were found in the proportion of patients who received each class of HF drug before and after PMVR. Up-titration, down-titration or changes in drug class occurred more frequently within blockers of the renin-angiotensin-aldosterone system. About a third of patients were on amiodarone at the time of MitraClip ${ }^{\circledR}$ procedure, with no significant changes during the entire follow-up.

\section{Discussion}

This study addressed the impact of MitraClip ${ }^{\circledR}$ on the incidence of VA among a multicenter cohort of patients with advanced HFrEF, moderate to severe FMR and ID who remained symptomatic despite GDOMT. The main finding of our report was that PMVR was associated with a significant decrease in overall VA and ICD therapies. Furthermore, a significant reduction in MR, NTproBNP and prevalence of severe $\mathrm{PH}$ and advanced $\mathrm{CKD}$, as well as a significant improvement in NYHA functional class were noted at 12 -month follow-up after MitraClip ${ }^{\circledR}$. Some issues should be highlighted regarding these results.

From a pathological perspective, MR prompts a volume overload to left cardiac chambers leading to increased myocardial stress and progressive LV remodeling (5) and 


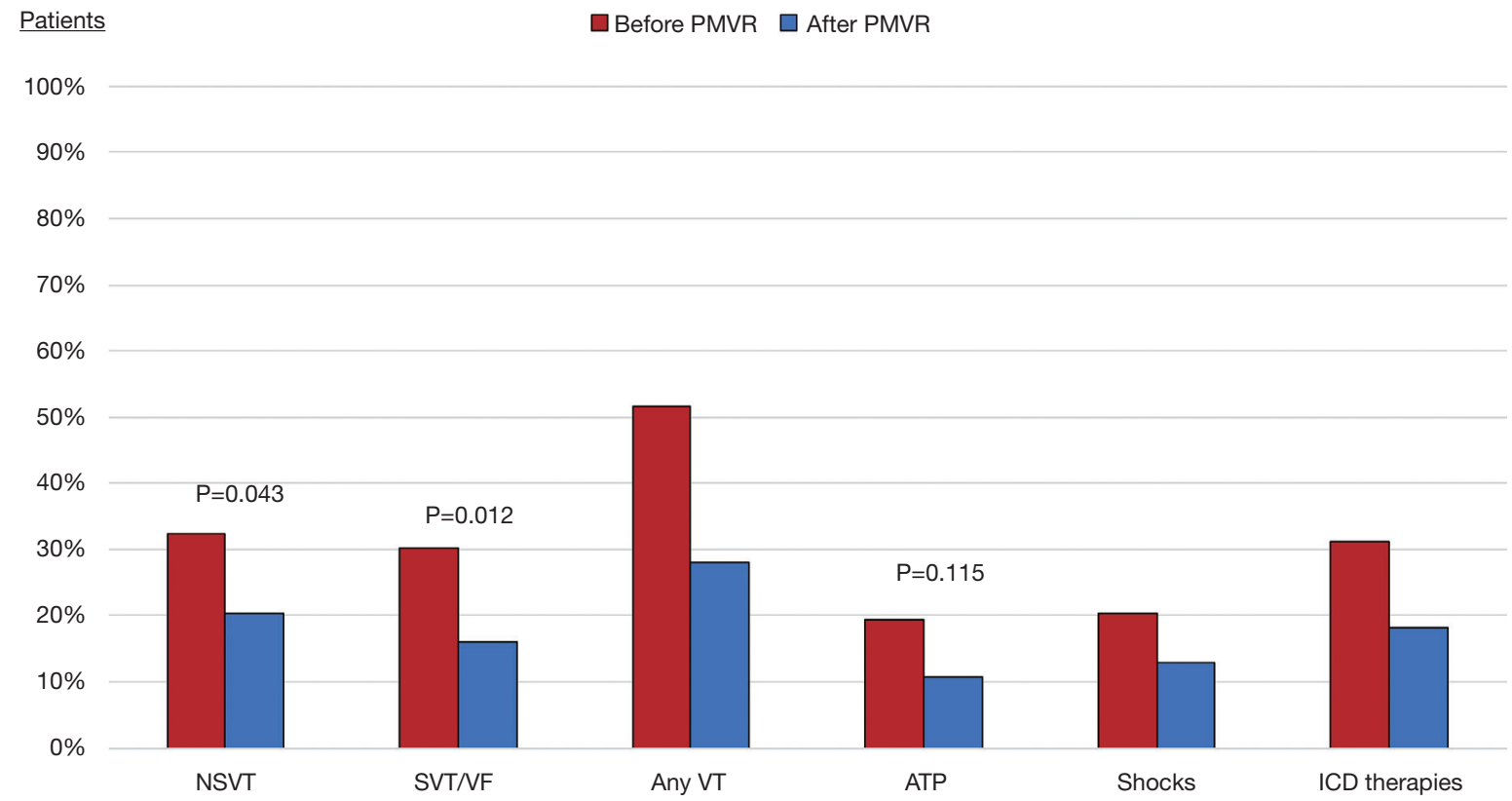

Figure 1 Proportion of patients who presented ventricular arrhythmias and antitachycardia device therapies before and after MitraClip ${ }^{\circledR}$. NSVT, non-sustained ventricular tachycardia; SVT, sustained ventricular tachycardia; VT, ventricular tachycardia; VF, ventricular fibrillation; ATP, antitachycardia pacing; ICD, implantable cardiac defibrillator.

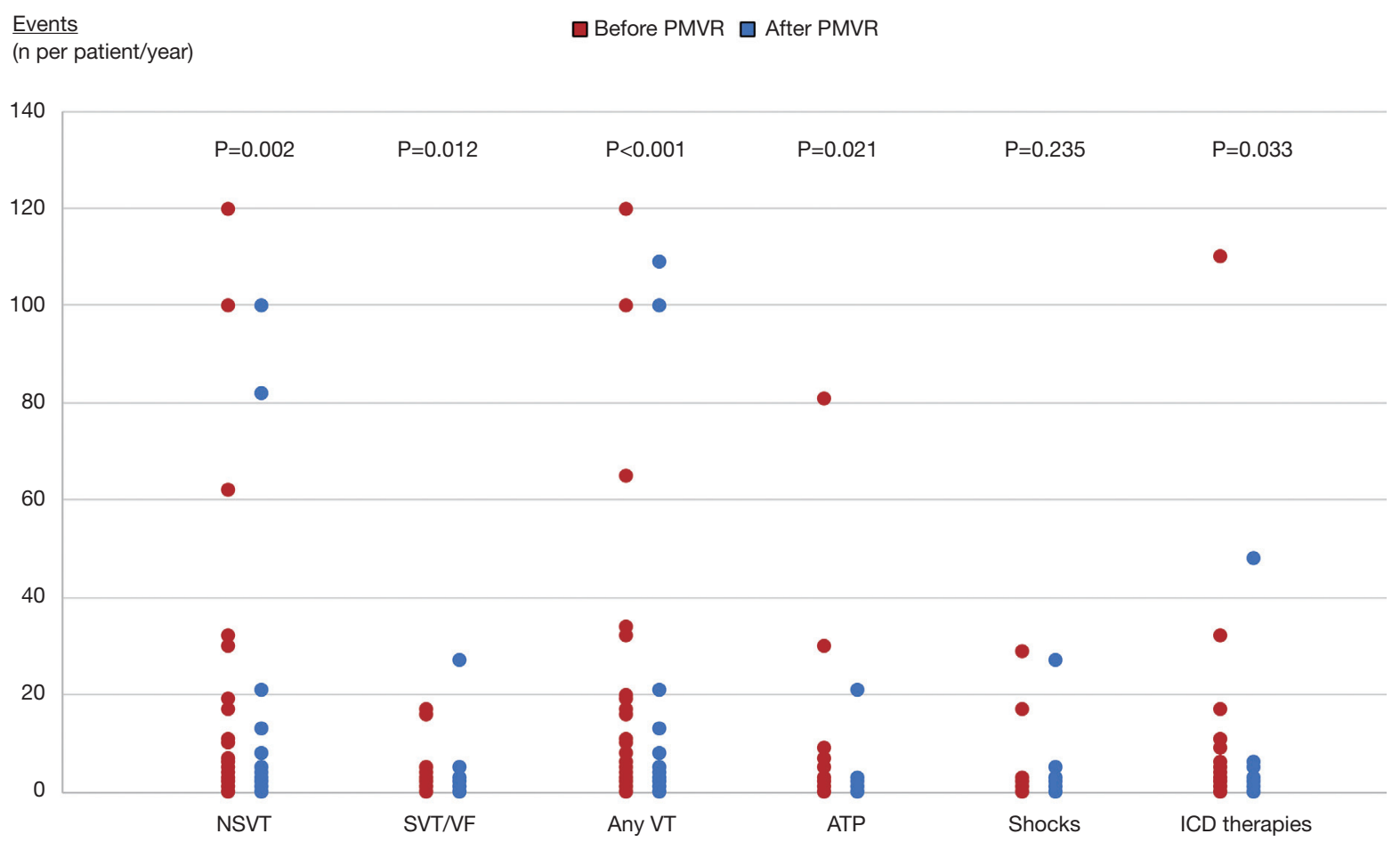

Figure 2 Incidence of ventricular arrhythmias and antitachycardia device therapies before and after percutaneous mitral valve repair. NSVT, non-sustained ventricular tachycardia; SVT, sustained ventricular tachycardia; VT, ventricular tachycardia; VF, ventricular fibrillation; ATP, antitachycardia pacing; ICD, implantable cardiac defibrillator. 
Page 6 of 10

A

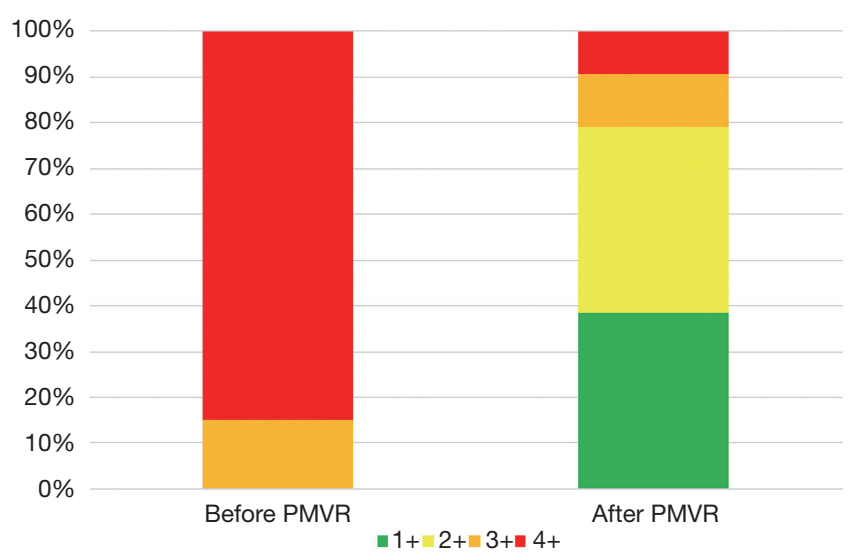

Benito-González et al. Ventricular arrhythmias in FMR after Mitraclip ${ }^{\circledR}$

\section{B}

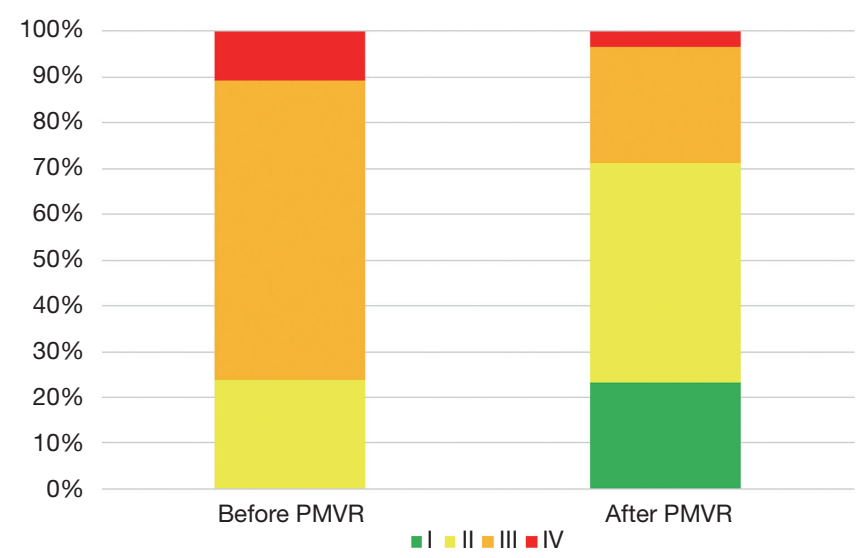

Figure 3 Changes in the degree of functional mitral regurgitation (A) and NYHA functional class (B) at 12-month follow-up after percutaneous mitral valve repair.

Table 3 Echocardiographic and clinical changes at one-year follow-up ( $\mathrm{n}=93$ )

\begin{tabular}{|c|c|c|c|}
\hline Clinical or echocardiographic findings & Before PMVR & 12-month follow-up & $P$ value* \\
\hline $1+$ & - & 38.4 & \\
\hline $2+$ & - & 40.7 & \\
\hline $3+$ & 15 & 11.6 & \\
\hline Severe pulmonary hypertension (\%) & 25.8 & 14.0 & 0.027 \\
\hline Left ventricular ejection fraction $(\mathrm{mL})$ & $29.2 \pm 6.1$ & $30.4 \pm 10.3$ & 0.312 \\
\hline Left ventricular end-diastolic volume (mL) & $231.8 \pm 90.0$ & $220.8 \pm 100.4$ & 0.142 \\
\hline Left ventricular end-systolic volume $(\mathrm{mL})$ & $165.6 \pm 70.7$ & $156.8 \pm 83.7$ & 0.153 \\
\hline II & 23.7 & 47.8 & \\
\hline III & 65.6 & 25.6 & \\
\hline IV & 10.8 & 3.3 & \\
\hline NTproBNP $(p g / m L)$ & $2,991[1,676-5,400]$ & $2,460[1,453-4,368]$ & 0.010 \\
\hline Chronic kidney disease with GFR $\leq 45 \mathrm{~mL} / \mathrm{min}(\%)$ & 43.0 & 26.9 & 0.004 \\
\hline
\end{tabular}

NYHA, New Your Heart Association; GFR, glomerular filtration rate.

fibrosis (15), both associated with the development of VA $(16,17)$. In fact, moderate to severe MR was independently associated with the incidence VA in patients with dilated cardiomyopathy (18). Theoretically, correcting MR may break the vicious circle of FMR, volume overload, LV remodeling and more FMR, preventing further disease progression and thus, reducing VA burden. In this regard, left ventricular unloading has been previously associated with a reduction in myocardial stress and arrhythmic burden in a preclinical model (19). 
Table 4 Pharmacological treatment for heart failure and antiarrhythmic drugs at the time percutaneous mitral valve repair was performed and at 12-month follow-up (n=93)

\begin{tabular}{|c|c|c|c|}
\hline Medical therapy & Baseline & 12-month Follow-up & $P$ value \\
\hline Decrease dose by $>50 \%$ or discontinue (\%) & - & 7.7 & \\
\hline Increase dose by $>100 \%$ or new drug class started (\%) & - & 7.7 & \\
\hline ACEI/ARBII/ARNI (\%) & 86.2 & 84.2 & 1.0 \\
\hline Increase dose by $>100 \%$ or new drug class started (\%) & - & 20.4 & \\
\hline Mineralocorticoid receptor antagonists (\%) & 74.2 & 67.0 & 0.263 \\
\hline Decrease dose by $>50 \%$ or discontinue $(\%)$ & - & 16.5 & \\
\hline Increase dose by $>100 \%$ or new drug class started (\%) & - & 7.9 & \\
\hline
\end{tabular}

ACEI, angiotensin converting enzyme inhibitor; ARB, angiotensin receptor blocker; ARNI, angiotensin receptor-neprilysin inhibitor.

Previous studies, in accordance with our research, reported an effective reduction in MR severity after PMVR (8), which translated into a significant increase in cardiac output and a significant reduction in LV filling pressures and $\mathrm{PH}$ in invasive observational series of advanced HFrEF (20). In parallel, in our series a significant reduction in NTproBNP and in the prevalence of severe $\mathrm{PH}$ were documented at 12-month follow-up. NTproBNP is considered a major non-invasive marker of myocardial stress and has been independently related with the risk of VA (21). Similar reductions in brain natriuretic peptides in patients with HFrEF and FMR have been reported before in observational studies (18) and, more recently, in the COAPT randomized controlled trial after PMVR. In a subanalysis of this trial, MitraClip ${ }^{\circledR}$ was related to a significant reduction in BNP at 6 and 12 months, while no significant changes were observed in the conservative arm (22).

Disease progression facilitates the development of arrhythmic triggers and substrate (23). Advanced NYHA functional class and impaired renal function, as markers of advanced HF, have been previously identified as independent predictors of sudden cardiac death and appropriate device therapies in patients with an ICD $(24,25)$. Parallelly to hemodynamic enhancement, clinical improvement after MitraClip ${ }^{\circledR}$ has been consistently found in patients with FMR (26), although conflicting results were reported in recent randomized controlled trials (RCTs) regarding the superiority of this therapy over standalone medical treatment $(8,27)$. Similarly, Wang et al. (28) published a statistically significant increase in GFR in patients with advanced CKD associated to the reduction in MR severity. As such, PMVR was related to a significant improvement in symptoms and to a reduction in the prevalence of advanced CKD at 12-month follow-up in our series.

On the contrary, although LV volumes tended to be lower at 12 -month, no significant $L V$ reverse remodeling was found in our cohort. In a recent meta-analysis including over 1,200 patients with FMR from 16 observational reports, a significant, albeit modest, favorable LA and LV remodeling was noted after PMVR (29). Nevertheless, these results were not reproduced in recent RCTs $(8,27)$. In the COAPT study, despite reductions in brain natriuretic peptides and favorable clinical outcomes, LV dimension did increase and LVEF was reduced over time, with less negative remodeling in the interventional group at 12-month follow-up (30).

VA burden is related to pump failure progression (23) and increased rates of re-hospitalizations for HF and death (31). Furthermore, VA and sudden cardiac death are a frequent cause of mortality in patients with advanced HF (32) and ICD shocks also impair their prognosis (33). Little information is available regarding the impact of MitraClip ${ }^{\circledR}$ in the occurrence of VA and defibrillation shocks. A reduction in the incidence of VA and ICD therapies after successful PMVR were found in a small cohort of patients with HFrEF and FMR who had either a pacemaker, ICD or CRT implanted (9). Similarly, Ledwoch et al. (10) 
documented by 24-hour electrocardiographic monitoring a reduction in ectopic ventricular activity, NSVT and SVT at 6-month follow-up after PMVR. Whether these changes have any impact on mortality, has not been evaluated. To date, conflicting results of recently published RCTs regarding the survival impact of MitraClip ${ }^{\circledR}$ implantation over stand-alone medical treatment in patients with FMR makes this question yet unsolved (34).

Pharmacological HF therapies have shown to improve clinical outcomes in patients with HFrEF (35). Furthermore, a positive impact on VA burden and in the incidence of sudden cardiac death in this population has also been reported for most HF drugs (23). In our study, no major changes in the proportion of patients treated with either beta-blockers, renin-angiotensin system inhibitors or mineralocorticoid receptor antagonists were documented before and at 1-year after PMVR. Nevertheless, mild to moderate changes in dosing and type of drug administration occurred within follow-up that could influence the VA burden and even the clinical outcome of our patients. Unfortunately, this relation could not be evaluated from the data obtained in our study.

\section{Limitations}

To the best of our knowledge this is the largest multicenter registry to address VA and ICD therapies in patients with HFrEF, FMR and ID undergoing PMVR. Nevertheless, our study has some limitations. First, the retrospective design might have introduced selection bias, some confounding variables associated to the incidence of VA could be missed or inaccurate event adjudication. At this regard, invasive and non-invasive dedicated antiarrhythmic therapies were taken into consideration. Thus, patients who underwent VT ablation or upgrade to CRT during the observation period were excluded and concomitant administration of amiodarone was evaluated before PMVR and after the one year follow-up. On the contrary, differences in device programming, changes in the dose of antiarrhythmic drugs as a result of a documented VA, metabolic disturbances and incidence of new ischemic coronary events or revascularization procedures were not addressed. Regarding arrhythmic events adjudication, most patients were under device home monitoring which facilitates accurate recordkeeping. Second, a multilevel analysis was not performed to evaluated differences in baseline characteristics in-between patients from different participating centers. Third, patients who died before completing one year follow-up after PMVR were not included in the analysis, which may have underestimated the incidence of VA after MitraClip ${ }^{\circledR}$ since those might be the sickest subgroup of patients. Four, no control group was enrolled.

\section{Conclusions}

In conclusion, PMVR was related to a reduction in arrhythmic burden and ICD therapies in our cohort. Given the inherent limitations of this study, the results reported should be interpreted with caution as hypothesis generating. Further investigation should be performed to confirm these findings and address their potential impact on clinical outcomes.

\section{Acknowledgments}

Funding: None.

\section{Footnote}

Provenance and Peer Review: This article was commissioned by the Guest Editor (Daniel Hernández-Vaquero) for the series "Structural Heart Disease: The Revolution" published in Annals of Translational Medicine. The article was sent for external peer review organized by the Guest Editor and the editorial office.

Conflicts of Interest: All authors have completed the ICMJE uniform disclosure form (available at http://dx.doi. org/10.21037/atm.2020.02.45). The series "Structural Heart Disease: The Revolution" was commissioned by the editorial office without any funding or sponsorship. REL, CG, XF and LNF are consultants for Abbott vascular and proctor for MitraClip ${ }^{\circledR}$. MT is consultant for Abbott Vascular, Boston Scientific, 4tech, CoreMedic. Speaker fees from Edwards Lifesciences. The authors have no other conflicts of interest to declare.

Ethical Statement: The authors are accountable for all aspects of the work in ensuring that questions related to the accuracy or integrity of any part of the work are appropriately investigated and resolved. The study was conducted in accordance with the Declaration of Helsinki (as revised in 2013). The study was approved by the local institutional review board as required at each participating centre. 
Open Access Statement: This is an Open Access article distributed in accordance with the Creative Commons Attribution-NonCommercial-NoDerivs 4.0 International License (CC BY-NC-ND 4.0), which permits the noncommercial replication and distribution of the article with the strict proviso that no changes or edits are made and the original work is properly cited (including links to both the formal publication through the relevant DOI and the license). See: https://creativecommons.org/licenses/by-nc$\mathrm{nd} / 4.0 /$.

\section{References}

1. Maggioni AP, Dahlström U, Filippatos G, et al. EURObservational Research Programme: Regional differences and 1-year follow-up results of the Heart Failure Pilot Survey (ESC-HF Pilot). Eur J Heart Fail 2013;15:808-17.

2. Saltzman HE. Arrhythmias and heart failure. Cardiology Clinics 2014;32:125-33.

3. Grigioni F, Enriquez-Sarano M, Zehr KJ, et al. Ischemic mitral regurgitation: long-term outcome and prognostic implications with quantitative Doppler assessment. Circulation 2001;103:1759-64.

4. Agricola E, Stella S, Figini F, et al. Non-ischemic dilated cardiopathy: Prognostic value of functional mitral regurgitation. Int J Cardiol 2011;146:426-8.

5. Enriquez-Sarano M, Akins CW, Vahanian A. Mitral regurgitation. Lancet 2009;373:1382-94.

6. Stolfo D, Ceschia N, Zecchin M, et al. Arrhythmic Risk Stratification in Patients With Idiopathic Dilated Cardiomyopathy. Am J Cardiol 2018;121:1601-9.

7. Boyle N. A Clinical Review of Ventricular Arrhythmias in Patients with Congestive Heart Failure. EMJ Cardiol 2019. [Epub ahead of print].

8. Stone GW, Lindenfeld J, Abraham WT, et al. Transcatheter Mitral-Valve Repair in Patients with Heart Failure. N Engl J Med 2018;NEJMoa1806640.

9. Benito-González T, Estévez-Loureiro R, Garrote-Coloma C, et al. Effect of Successful Edge-to-Edge Mitral Valve Repair on Ventricular Arrhythmic Burden in Patients With Functional Mitral Regurgitation and Implantable Cardiac Devices. Am J Cardiol 2019. [Epub ahead of print].

10. Ledwoch J, Nommensen A, Keelani A, et al. Impact of transcatheter mitral valve repair on ventricular arrhythmias. Europace 2019;21:1385-91.

11. Lang RM, Badano LP, Mor-Avi V, et al. Recommendations for cardiac chamber quantification by echocardiography in adults: An update from the American society of echocardiography and the European association of cardiovascular imaging. Eur Heart J Cardiovasc Imaging 2015;16:233-70.

12. Lancellotti P, Tribouilloy C, Hagendorff A, et al. Recommendations for the echocardiographic assessment of native valvular regurgitation: An executive summary from the European Association of Cardiovascular Imaging. Eur Heart J Cardiovasc Imaging 2013;14:611-44.

13. Stone GW, Adams DH, Abraham WT, et al. Clinical Trial Design Principles and Endpoint Definitions for Transcatheter Mitral Valve Repair and Replacement: Part 2: Endpoint Definitions A Consensus Document from the Mitral Valve Academic Research Consortium. J Am Coll Cardiol 2015;66:308-21.

14. Ermis C, Seutter R, Zhu AX, et al. Impact of upgrade to cardiac resynchronization therapy on ventricular arrhythmia frequency in patients with implantable cardioverter-defibrillators. J Am Coll Cardiol 2005;46:2258-63.

15. Kitkungvan D, Nabi F, Kim RJ, et al. Myocardial Fibrosis in Patients With Primary Mitral Regurgitation With and Without Prolapse. J Am Coll Cardiol 2018;72:823-34.

16. Yokokawa M, Tada H, Koyama K, et al. The Characteristics and Distribution of the Scar Tissue Predict Ventricular Tachycardia in Patients with Advanced Heart Failure. Pacing Clin Electrophysiol 2009;32:314-22.

17. Zeltser I, Gaynor JW, Petko M, et al. The roles of chronic pressure and volume overload states in induction of arrhythmias: An animal model of physiologic sequelae after repair of tetralogy of Fallot. J Thorac Cardiovasc Surg 2005;130:1542-8.

18. Berardini A, Biagini E, Saia F, et al. Percutaneous mitral valve repair: The last chance for symptoms improvement in advanced refractory chronic heart failure? Int J Cardiol 2017;228:191-7.

19. Ishikawa K, Watanabe $S$, Lee $P$, et al. Acute Left Ventricular Unloading Reduces Atrial Stretch and Inhibits Atrial Arrhythmias. J Am Coll Cardiol 2018;72:738-50.

20. Geis NA, Pleger ST, Bekeredjian R, et al. Haemodynamic effects of percutaneous mitral valve edge-to-edge repair in patients with end-stage heart failure awaiting heart transplantation. ESC Heart Fail 2018;5:892-901.

21. Levine YC, Rosenberg MA, Mittleman M, et al. B-type natriuretic peptide is a major predictor of ventricular tachyarrhythmias. Heart Rhythm 2014;11:1109-16.

22. Abraham W, Lindenfeld J, Mack M, et al. 1386Reduction of mitral regurgitation in patients with heart failure and 
secondary mitral regurgitation: relationship between changes in brain natriuretic peptide and outcomes from the COAPT trial. Eur Heart J 2019. [Epub ahead of print].

23. Santangeli P, Rame JE, Birati EY, et al. Management of Ventricular Arrhythmias in Patients With Advanced Heart Failure. J Am Coll Cardiol 2017;69:1842-60.

24. Kreuz J, Balta O, Linhart M, et al. An impaired renal function and advanced heart failure represent independent predictors of the incidence of malignant ventricular arrhythmias in patients with an implantable cardioverter/ defibrillator for primary prevention. Europace 2010;12:1439-45.

25. Saxon LA, Bristow MR, Boehmer J, et al. Predictors of sudden cardiac death and appropriate shock in the Comparison of Medical Therapy, Pacing, and Defibrillation in Heart Failure (COMPANION) Trial. Circulation 2006;114:2766-72.

26. De Rosa R, Silverio A, Baldi C, et al. Transcatheter repair of functional mitral regurgitation in heart failure patients: A meta-analysis of 23 studies on mitraclip implantation. Circ J 2018;82:2800-10.

27. Obadia JF, Messika-Zeitoun D, Leurent G, et al. Percutaneous Repair or Medical Treatment for Secondary Mitral Regurgitation. N Engl J Med 2018;379:2297-306.

28. Wang A, Sangli C, Lim S, et al. Evaluation of renal function before and after percutaneous mitral valve repair. Circ Cardiovasc Interv 2015. doi: 10.1161/ CIRCINTERVENTIONS.113.001349.

29. Megaly M, Khalil C, Abraham B, et al. Impact of

Cite this article as: Benito-González T, Freixa X, Godino C, Taramasso M, Estévez-Loureiro R, Hernandez-Vaquero D, Serrador A, Nombela-Franco L, Grande-Prada D, Cruz-González I, San Antonio R, Galasso M, Gavazzoni M, Garrote C, Portolés-Hernández A, Avanzas P, Fernández-Vázquez F, Pascual I. Ventricular arrhythmias in patients with functional mitral regurgitation and implantable cardiac devices: implications of mitral valve repair with Mitraclip ${ }^{\circledast}$. Ann Transl Med 2020;8(15):956. doi: $10.21037 /$ atm.2020.02.45

\section{Benito-González et al. Ventricular arrhythmias in FMR after Mitraclip ${ }^{\circledR}$}

Transcatheter Mitral Valve Repair on Left Ventricular Remodeling in Secondary Mitral Regurgitation: A MetaAnalysis. Struct Hear 2018;24748706.2018.1516912.

30. Asch FM, Grayburn PA, Siegel RJ, et al. Echocardiographic Outcomes after Transcatheter Leaflet Approximation in Patients with Secondary Mitral Regurgitation: The COAPT Trial. J Am Coll Cardiol 2019;74:2969-79.

31. de Sousa MR, Morillo CA, Rabelo FT, et al. Nonsustained ventricular tachycardia as a predictor of sudden cardiac death in patients with left ventricular dysfunction: A meta-analysis. Eur J Heart Fail 2008;10:1007-14.

32. Pokorney SD, Al-Khatib Sana M, Sun J, et al. Sudden cardiac death after acute heart failure hospital admission: insights from ASCEND-HF. Eur J Heart Fail 2018;20:525-32.

33. Bazoukis G, Tse G, Korantzopoulos P, et al. Impact of Implantable Cardioverter-Defibrillator Interventions on All-Cause Mortality in Heart Failure Patients - A MetaAnalysis. Cardiol Rev 2019;27:160-6.

34. Benito-González T, Estévez-Loureiro R, Villablanca PA, et al. Percutaneous mitral valve repair vs. stand-alone medical therapy in patients with functional mitral regurgitation and heart failure. Cardiovasc Revascularization Med 2019. [Epub ahead of print].

35. Crespo-Leiro MG, Metra M, Lund LH, et al. Advanced heart failure: a position statement of the Heart Failure Association of the European Society of Cardiology. Eur J Heart Fail 2018;20:1505-35. 


\section{Supplementary}

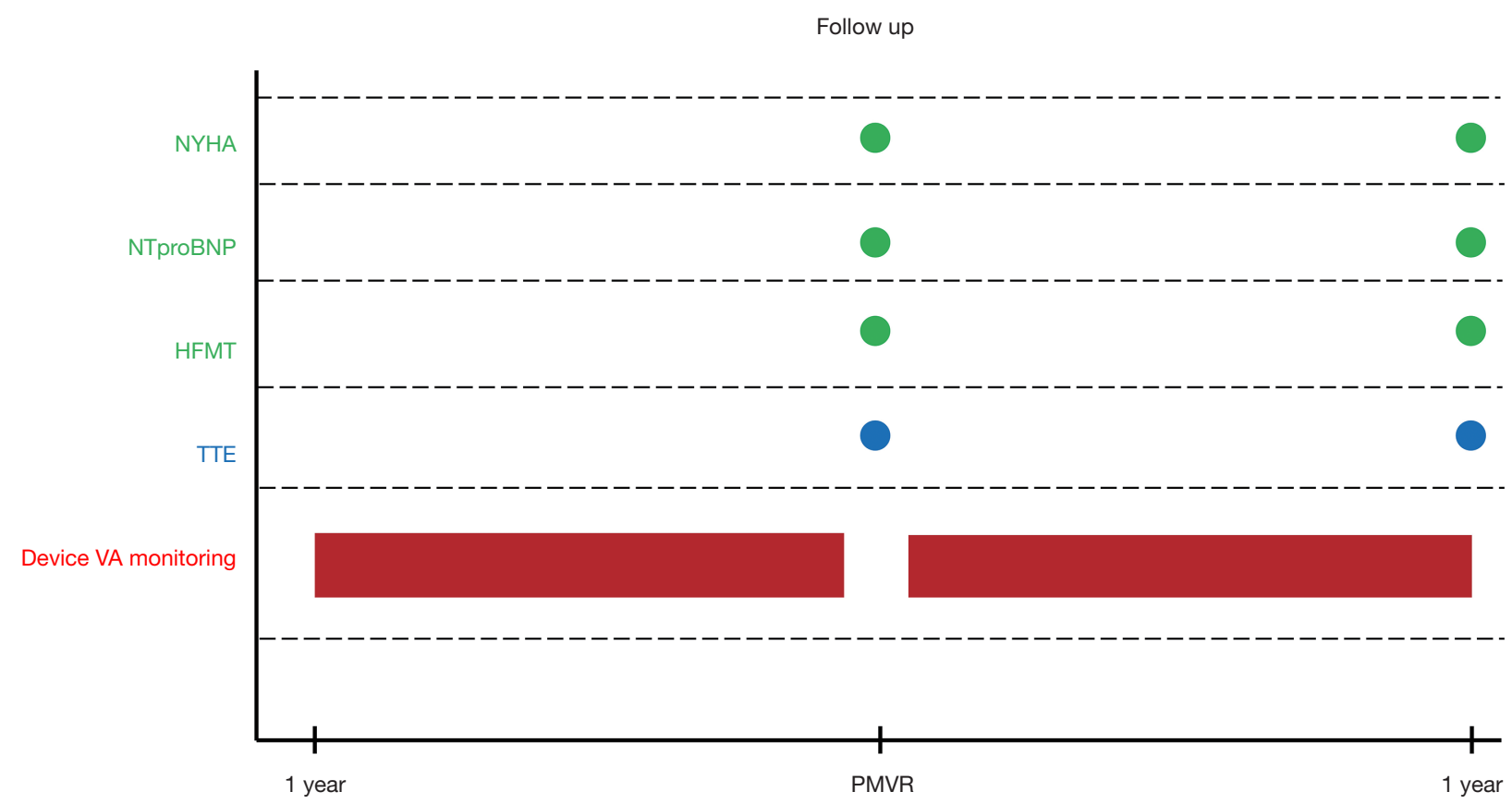

Figure S1 Study design flow chart. NYHA, New York Heart Association; HFMT, Heart Failure Medical Therapy; TTE, transthoracic echocardiogram; PMVR, percutaneous mitral valve repair; VA, ventricular arrhythmias. 